\title{
Book review: Drawing Lithic Artefacts
}

\author{
Jayson Gill
}

Department of Anthropology, University of Connecticut. 354 Mansfield Road, Storrs, Connecticut 06269,

U.S.A. Email: jayson.gill@uconn.edu

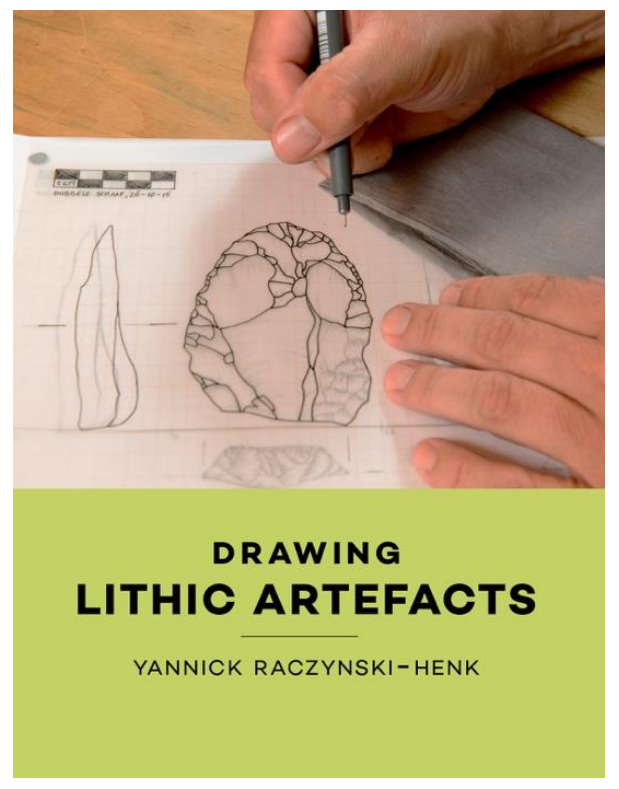

\section{Drawing Lithic Artefacts}

By Yannick Raczynski-Henk

Sidestone Press, 2017, pp. 50. ISBN 978-908-890-530-8

https://www.sidestone.com/books/drawing-lithic-artefacts

Drawing Lithic Artefacts is a brief, yet detailed guide for the scientific illustration of stone implements. The book was originally published in Dutch as Het Tekenen Van Vuurstenen Artefacten in 2016 by Sidestone Press. The author, Yannick Raczynski-Henk, has over 14 years of experience as a professional archaeologist in the Netherlands; he is also involved in several archaeological projects in the Southern Caucasus and is currently an independent $\mathrm{PhD}$ researcher at Leiden University. The book works well as both an introduction to lithic illustration for the beginner and as a helpful reference for the seasoned professional. The subject matter is approached with a focus on the appropriate representation of information, rather than illustration as an artistic endeavour. With this focus, the book also

Published by the School of History, Classics and Archaeology, University of Edinburgh ISSN: 2055-0472. URL: http://journals.ed.ac.uk/lithicstudies/

This work is licensed under a Creative Commons Attribution 2.5 UK: Scotland License. 
serves as a rudimentary introduction to lithic analysis, as proper identification and orientation of lithics and their landmarks is paramount to their accurate illustration.

While the book goes through conventions for drawing most standard lithic classes, it largely brushes over the illustration of cores, except for a brief mention on orientation. Some variations of core technology can be complex and it is this complexity that an illustrator would want to convey in any visual representation. This omission is an unfortunate drawback to an otherwise well-rounded guide to drawing lithics. However, the book's short chapter format, friendly yet professional tone, and avoidance of overly complex jargon makes it an easily accessible, informative read. Any specialized, or technical, terminology is well covered in the extensive glossary, which adds to its approachability for the uninitiated.

The book is divided into 7 chapters. Chapter 1 serves as an introduction and discusses illustration as a means of conveying information versus being an art form. Furthermore, the introductory chapter addresses the utility of illustration in the digital age and compares the process to technology such as 3D scanning. Chapter 2 introduces the conventions of lithic illustration, such as different standards for projection and symbols used to denote flake directionality, polishing, and other phenomena. Chapters 3 to 6 take the reader through the step by step process of illustration, from preparation to digital editing for publication.

The third chapter of the book dives into the supplies and other preparations needed prior to beginning a drawing. Not only does this chapter explain the use of different supplies, it makes the reader consider appropriate work areas in terms of lighting and comfort. This chapter further brings to light specialized modes of analysis, such as residue analysis, that should be undertaken, if so desired, before the handling of the artefact by an illustrator. Chapter 4 is an in-depth walkthrough of the process of producing a pencil drawing, from start to finish. The fifth chapter presents a guide to inking a finished pencil drawing and providing additional finishing touches. The next chapter in the book, chapter 6 , is a discussion of the final steps in preparing an illustration for publication, including scanning, digital editing, and advice on last minute cosmetic alterations. Chapter 7 rounds the book out with some final words of encouragement for those just beginning to illustrate lithic artefacts.

The book's few shortcomings are easily overlooked due to the widely accessible nature of the text. Furthermore, the inclusion of illustration examples, photography of the drawing process, and other helpful figures strengthen this addition to the literature on artefact illustration. The book serves as a condensed introduction and reference guide for lithic illustration that acts to replace older, more cumbersome, volumes that can be expensive and hard to find. Perhaps Drawing Lithic Artefacts can best be described as a portable field guide to lithic illustration that feels just as at home on a coffee table as it does in a field lab. 